Davos, December 2010

\title{
Celebrating a successful first year of EBSJ
}

Fig 1 Members of the Editorial Board at the EBSJ reception during the AOSpine Courses in Davos, Switzerland, December 15, 2010.

From left to right:

Karsten Wiechert, Co-Managing Editor-in-Chief; KV Menon, Regional Editor AOSpine India; Bryan Ashman, Regional Editor AOSpine Pacific; Jens Chapman, Editor-in-Chief and Scientific Editor-in-Chief; Andrea Skelly, Deputy Editor Scientific Methodology; Jeffrey Wang, Co-Managing Editor-in-Chief; Michael Fawcett, Community Development Manager AOSpine International; Kathrin Lüssi, Deputy Editor Publishing; Luiz Roberto Vialle, Senior Editor-in-Chief.

Fig 2 EBSJ reception at AOSpine Courses in Davos.

Fig 3 Cutting-edge evidence: Jens Chapman, Andrea Skelly, and Luiz Roberto Vialle.
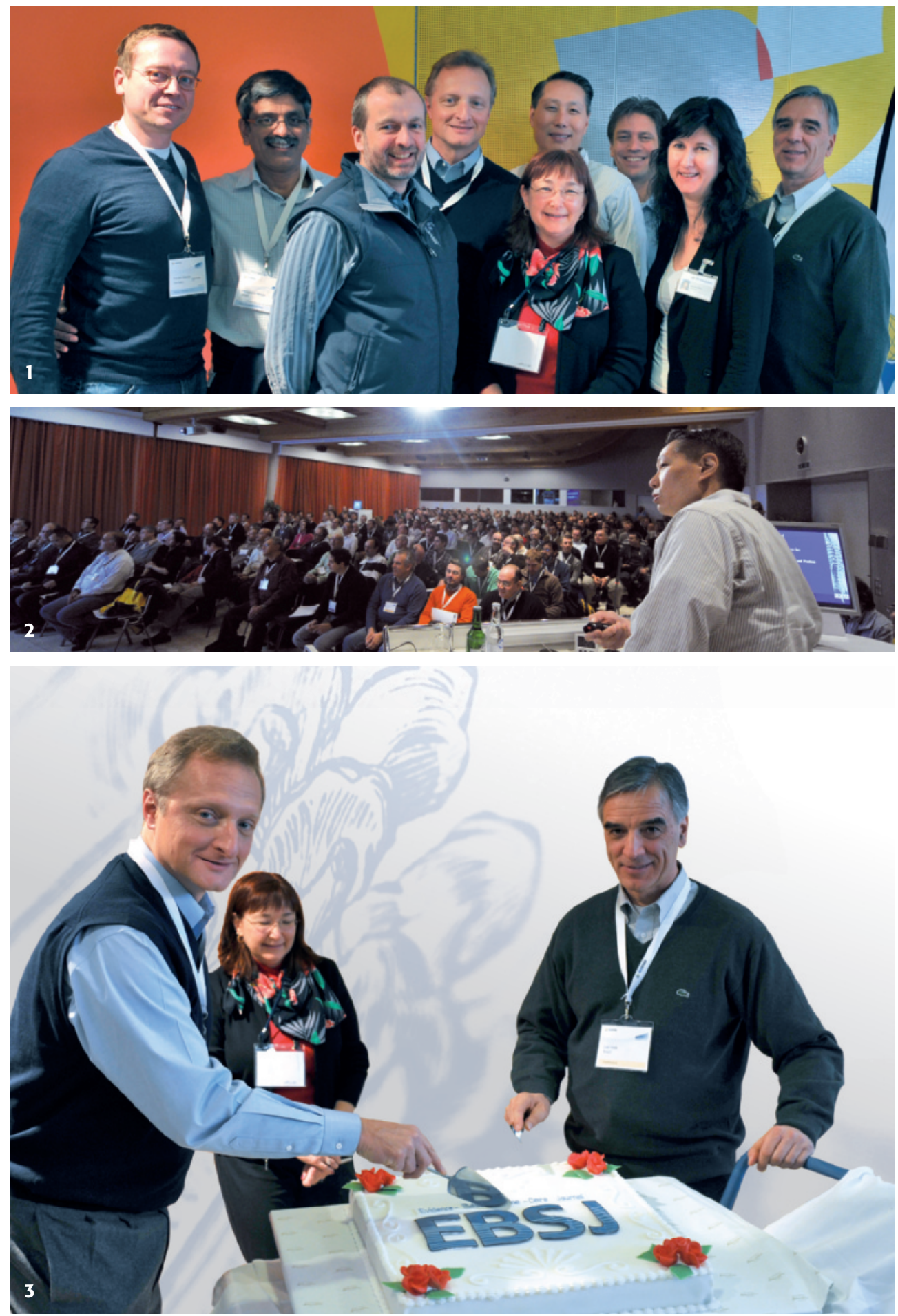